\title{
Artículo 48 del Código Penal, ¿justicia versus delincuencia?
}

Luego de que han pasado más de dos años desde que el tema pasó a ser prioritario en la agenda pública de puntos de discusión, sobre la delincuencia se ha dicho mucho - tal vez demasiado - sin que hasta la fecha se haya logrado alcanzar una visión englobante que explique satisfactoria y coherentemente sus causas, manifestaciones y consecuencias. Fuera de algunas excepciones, a la delincuencia - sea común u organizada- se le ha abordado parcializadamente y con intenciones ajenas a las que el problema requiere para ser comprendido y solucionado. Lo que es evidente ha sido pasado por alto: ningún plan ni medida que se aplique rendirá los frutos necesarios para frenar la delincuencia mientras no se disponga de esta visión de conjunto sobre el fenómeno.

Pero en El Salvador, la problemática va aún más allá de la ausencia de este elemento tan esencial: el gobierno, en su afán de comercializar al país en el exterior y realzar su gestión, ha sido reacio en reconocer la verdadera magnitud de la delincuencia y ha minimizado la responsabilidad que le corresponde en su solución. Hasta la fecha, el papel del Ejecutivo se ha reducido a fustigar a las instancias que la opinión pública y los medios de comunicación han convertido en responsables del fracaso en la lucha contra la delincuencia.

Ante la falta de una visión y dirección claras que vinculen su trabajo, tanto la Policía Nacional Civil como la Corte Suprema de Justicia o los jueces sólo han sabido montar una comidilla de enrevesamientos, contradicciones y acusaciones mutuas. Cuando los medios señalan que es la incom- petencia de los jueces lo que hace que la Policía Nacional Civil no cumpla con su labor, los primeros atacan la poca preparación de los agentes o el desconocimiento de éstos de las normas procedimentales apegadas al derecho para aprehender a un delincuente; a la inversa, cuando los medios o el Presidente de la República dirigen su dedo acusador contra la Policía Nacional Civil o el Ministerio de Seguridad Pública, ambos contraargumentan que los códigos penales y los jueces defienden más los derechos de los delincuentes que los de la población, atando así las manos de la Policía Nacional Civil para perseguir a los criminales.

Algo que complica aún más la problemática es la presión que ejercen los medios, en su pretendido papel de canalizadores de las exigencias y necesidades ciudadanas, y la actitud que ante ello asumen las instancias gubernamentales responsables de combatir a la delincuencia. En esta relación, la acriticidad y el manejo político de la opinión pública han sido fatalmente preponderantes. Por un lado, las instancias gubernamentales, en la confusión y falta de conocimiento del problema delincuencial que las caracteriza, han sido especialmente vulnerables a los señalamientos que emanan de la prensa y la opinión pública (expresada en encuestas o manifiestos ciudadanos). Se ha perdido de vista que la opinión ciudadana o la de los medios no siempre es la más acertada o la más calificada para discutir la validez de las medidas que se idean o aplican para combatir a la delincuencia. Ciertamente, la voz de la ciudadanía debe ser tomada en cuenta a la hora de discutir el asunto que sea -en especial, en aquellos que afectan sus for- 
mas de convivencia-, pero ello no disculpa de la necesidad del análisis técnico y la reflexión serena y lúcida.

Por otro lado, y de manera complementaria, esta vulnerabilidad se ha visto alimentada en buena medida por la politización que de las cuestiones nacionales se hace. El "quedar bien" ha primado hasta ahora sobre el "actuar bien", tanto en los partidos políticos como en las instancias gubernamentales. Ya sea con el fin de atraer votos o granjcarse el beneplácito de la opinión pública, muchos de los actores sociales involucrados en la lucha contra la delincuencia no han dudado en convertirse en veletas de las exigencias y manifestaciones ciudadanas, aun cuando éstas han sido, en no pocas ocasiones, irracionales e infundadas.

Uno de los ejemplos más claros de esto ha sido el ir y venir de las declaraciones del Presidente de la República sobre la cuestión: cuando las encuestas han mostrado que los consultados opinan que la delincuencia ha aumentado, Calderón Sol se ha manifestado en el mismo sentido -incluso cuando no se cuenta con estadísticas oficiales que le den valide $z$ a esta percepción-; si buena parte de la población reclama la pena de muerte como respucsta a los delincuentes, el Presidente no duda en defenderla y exigir su aprobación constitucional.

En este marco debe abordarse la polémica que en las últimas semanas se ha desatado sobre el Código Penal y Procesal Penal, particularmente sobre el artículo 48 del primero. La controversia nació a raíz del señalamiento de los medios de que la aplicación de dicho artículo pondría automáticamente en libertad a "miles" de reos, debido a que éste norma que "la detención provisional que la persona haya sufrido por el hecho que fuere condenada, se abonará a la pena a razón de un día de prisión por cada día de detención provisional durante los primeros seis meses, de dos días de prisión por cada día de detención provisional, por el tiempo que supere los seis meses y no exceda de un año, $y$, por tres días de prisión por cada día de detención provisional por el tiempo que exceda de un año".

De esta manera si, por ejemplo, se diera el caso -nada extraordinario en el sistema judicial salvadoreño- de que un sujeto hubiera estado en detención provisional durante 8 meses o 240 días antes de que se le condenara a purgar 4 años de prisión, acogiéndose a los beneficios del artículo

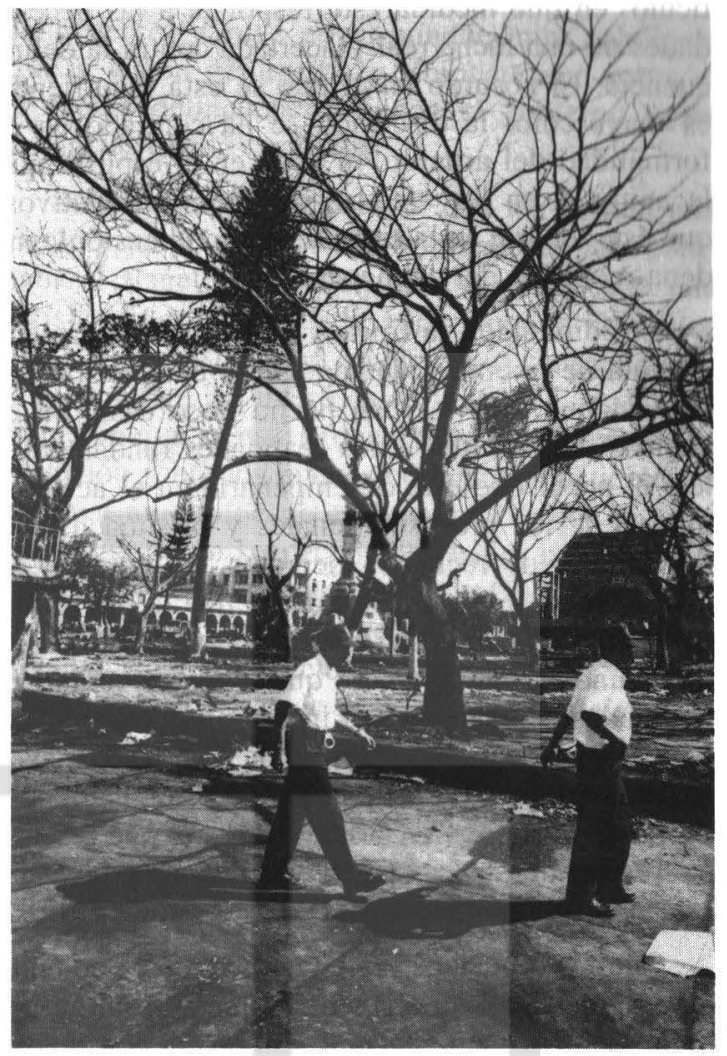

48 del Código Penal, su sentencia se vería reducida en 16 meses o 480 días, como resultado de multiplicar por dos cada uno de los días que permaneció recluido sin estar condenado y restarle este resultado al tiempo de la pena. En otras palabras, en este caso hipotético, el recluso sólo tendría que cumplir una sentencia de 2 años 8 meses para salir libre y habría pasado en prisión un total de 3 años 4 meses. Lógicamente, los resultados de aplicar esta ecuación son más dramáticos en los casos en los que el período de detención provisional ha sido lo suficientemente largo como para reducir la pena a unos cuantos meses u obligar al juez a poner al recluso en libertad en el momento mismo en el que emite su sentencia.

Como era de esperarse, las reacciones de la Asamblea Legislativa, la Corte Suprema de Justicia (CSJ) y el Organo Ejecutivo no han sido las más afortunadas: azuzados por reportajes que han obviado muchos detalles y han magnificado desmedidamente otros, las tres instancias se han lanzado a una confusa discusión jurídica que deja de lado lo que debería ser la preocupación fundamental en la interpretación y aplicación del citado ar- 
tículo: en qué medida éste responde a las necesidades de una lucha real y acertada contra la delincuencia. El absurdo en el que se está incurriendo es mayúsculo: la discusión se ha centrado en la formalidad del artículo 48 y no en el espíritu que le anima y en los efectos, positivos o negativos, que éste tendría en la correlación aprehensión-condena-reclusión del delincuente.

Los diputados, la Corte y el Presidente, haciendo gala de miopía y demagogia - unos en mayor medida que otros-, han hecho poco caso, en el análisis del artículo, a dos realidades fundamentales: el papel que éste desempeñaría en el aceleramiento de los procesos penales y la situación de los centros de reclusión del país. Al parecer, lo que hasta ahora ha interesado es que la población percibirá que con el artículo se acortarán las penas de algunos reos (pretender que todos se verán beneficiados es una falsedad insostenible $o$ al menos un mero juicio de valor sin fundamentos técnicos), soslayando que una proporción de éstos han debido pasar más años en prisión que los que les corresponderían por sus penas y que una de las causas de la sobrepoblación carcelaria reside en ello.

Que los diputados pretendan reducir la polémica despojándola del elemento carcelario no es extraño, dada la negligencia e ignorancia con la que suclen abordar el ejercicio legislativo (en el colmo del absurdo, los diputados han declarado que desconocían los alcances y las repercusiones de un artículo que había sido aprobado por ellos mismos). Sin embargo, la actitud de los juristas y de algunos funcionarios de la Corte Suprema de Justicia es menos comprensible, en especial cuando se revisa la Memoria de Labores Junio 1997-Mayo $1998 \mathrm{del}$ Ministerio de Justicia. En ella se afirma que "la población del Sistema Penitenciario atendida por situación jurídica reflcja un porcentaje total de 26 por ciento de condenados y un 74 por ciento de procesados (ver Gráfica 1), mostrándose la lentitud en los procesos en la aplicación de justicia a los internos; este comportamiento se mantiene durante el período presentado, resultados que demuestran que los instrumentos legislativos utilizados hasta abril de 1998 no eran efectivos para la realidad de los problemas delictivos, lo que implica que el sistema de justicia penal actúa en muy modestas condiciones y el sistema penitenciario ha continuado albergando internos que no han sido juzgados".

\section{Gráfica 1 \\ Población interna atendida por situación jurídica}

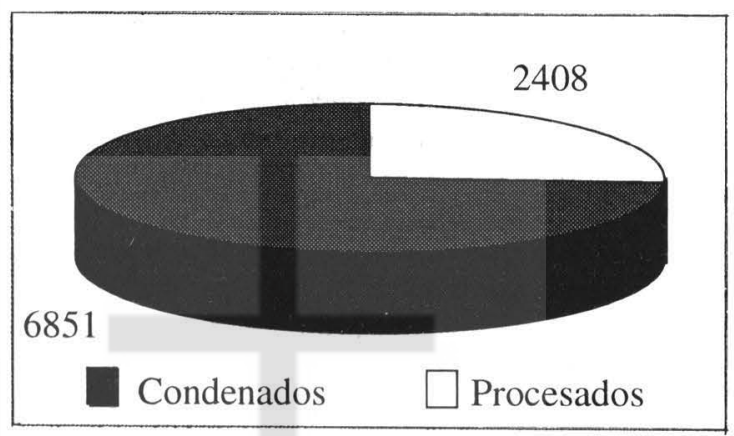

Fuente: Ministerio de Justicia.

Con el horizonte que describe el Ministerio de Justicia es más fácil hacerse una idea de los verdaderos objetivos del artículo 48: por un lado, convertirse en un instrumento legislativo efectivo para compensar la Ientitud de la aplicación de la justicia a los que han sido detenidos en los centros penitenciarios del país; por el otro, servir como una medida que presione a los jucces a resolver con prontitud la siluación judicial de los detenidos, so pena de verse obligados a que se reduzcan, en algunos casos considerablemente, la pena. No se trata, como se ha querido hacer creer, que el artículo en mención haya sido diseñado sólo para beneficiar o actuar a favor de los reos - que ciertamente lo hace-, se trata más bien de sanear una problemática anterior: un sistema judicial que permite que individuos que han sido apresados acusados de cometer delitos pasen largas temporadas en la cárcel - permitiendo así la sobrepoblación carcelaria - sin haber sido condenados ni dictadas sus sentencias. Así pues, el nudo gordiano de la polémica no es o no debería de ser el artículo en sí mismo, sino más bien la vergonzosa situación de la aplicación de la justicia en el país y las consecuencias que de ello se derivan para afrontar efectivamente a la delincuencia.

No se trata aquí de alirmar que la discusión del artículo es injustificada, sino más bien de señalar que en ella deben tenerse en cuenta elementos desde todo punto de vista más importantes que complacer a la opinión publica o librarse del costo político de llevar a buen término una normativa pe- 
nal, que el desconocimiento y afán draconiano de la ciudadanía vuelve impopular. De la manera en que la discusión está siendo conducida, la derogación, modificación o traslado al Código Procesal Penal del mencionado artículo, más que resolver un problema coyuntural, posiblemente termine incendiando aún más una situación ya explosiva: la incapacidad de los centros penitenciarios para acoger reos en condiciones mínimamente humanas (que incide directamente en su posibilidad de dar el salto de meros lugares de retención a instituciones de readaptación social) y el atascamiento judicial que vuelve inoperante la cabal aplicación de la justicia.

Por otra parte, y aún más importante, la encendida polémica que se ha desatado en torno al artículo 48 obliga a revisar cuidadosamente lo que se está entendiendo cuando se habla de proporcionar armas para la luchar contra la delincuencia. En el esquema cerrado y desvinculante que se está manejando, la aplicación, desde abril de este año, de los Códigos Penal y Procesal Penal se percibe como un obstáculo para la actuación policial, como una muestra de la insolidaridad que existe en el interior de las entidades responsables de aplicar justicia para con los agentes que aprehenden a los delincuentes. Grave error, aunque muy coherente con la visión deformada y simplista que sobre el problema delincuencial tienen el gobierno y las instancias que lo componen.

Sólo en un contexto en el que no existen una visión y un plan globales e integradores para combatir el flagelo delincuencial es posible que una legislación, que pretende hacer imperar el valor justicia, sea vista como un elemento contradictorio y nocivo para los intereses de la ciudadanía. De la forma en que se está procediendo y encauzando la discusión sobre los nuevos códigos, la justicia será un ideal muerto desde el momento en que la policía capture a un sospechoso de haber cometido un delito, puesto que pesará más el afán de excluirlo de la sociedad que las pruebas y los procedimientos que validen su detención y reclusión. Siendo así, no será disparatado esperar que, paralelamente al imperio de violencia que la delincuencia ha instalado en nuestro país, se configure un sistema judicial en el que las arbitrariedades y las equivocaciones procedimentales carecerán de mecanismos para ser detectadas y remediadas.

\section{Henry Marcel Vargas Escolero}

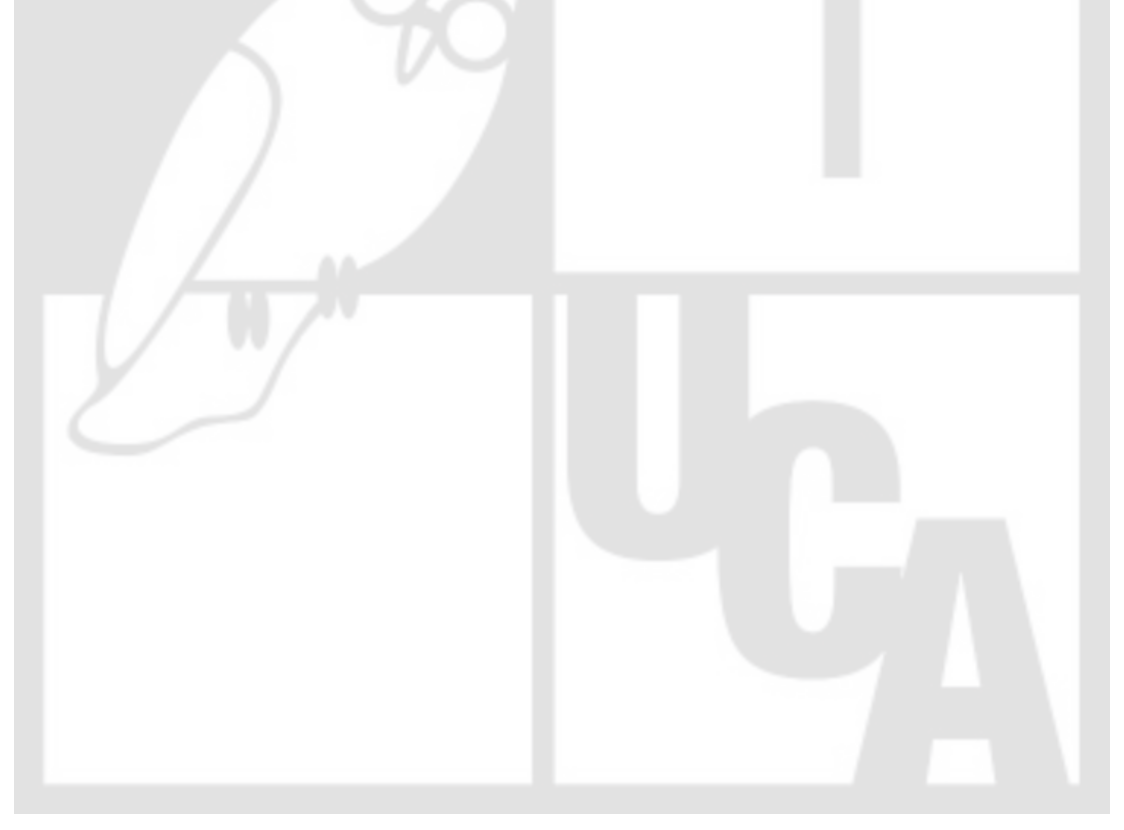

